\title{
Application of Modern Information Technologies in the Formation of Collective Design Competencies on the Example of Group Management of Heterogeneous Robots
}

\author{
Irina K. Romanova ${ }^{1 *}$ \\ ${ }^{1}$ Bauman Moscow State Technical University, 2nd Baumanskaya str., 5/1, 105005, Moscow, Russia
}

\begin{abstract}
The subject of these studies is to propose an approach to the formation of collective design competencies in the new digitalization environment. The relevance of the task in various fields of activity is shown. It is noted that while the latest information technologies, which appeared in the era of universal digitalization, are not yet sufficiently applied to build the competencies of designers as part of collective activities, the training of specialists is mainly carried out as part of individual projects. The studies were conducted on the basis of the actual applied task of collective design of group control of heterogeneous robots. The unique relationship of the object (group control) and the method of its research (group parallel design) is noted. A connection is established between the features of the ongoing project of group control of robots and the formation of in-depth competencies in the training of specialists in robotics and mechatronics. New representations of functional models are formed taking into account the needs of new information technologies. Within the framework of parallel and compositional design technologies based on CDP4 TM and System Composer TM, models have been obtained that implement functional schemes for group control of heterogeneous robots in two versions, suitable for use both for educational purposes to form team design competencies and for real projects.
\end{abstract}

\section{Introduction}

\subsection{Competencies and Project Approach}

The main competencies, as shown by the implementation of the International Project for the Assessment and Teaching of Skills and Competences of the XXI Century (ATC21S), which are currently in demand by society and business, are as follows:

- Skill of critical thinking;

- Skill of collective solving complex problems;

- Ability to think outside the box and flexibly;

* Corresponding author: irina.romanova@bmstu.ru 
- The ability to understand the meanings, incl. the meanings of many meanings and subtexts;

- Social intelligence;

- Development of project thinking;

- Entrepreneurial ability - the ability to find new ideas and turn them into businesses.

Particular emphasis should be placed in this list on project thinking, which in the long term is revealed in social capital and serves the social progress of society. The project approach is a tool for implementing the development strategy of specific companies and is closely related to the concept of the project, which has the following features [1]:

- The main objective of projects is to achieve goals;

- It is necessary to simultaneously comply with the financial and time limits of the project;

- The concept of "project" implies the concept of "uniqueness", which can be expressed either in the creation of a fundamentally new one or in the presence of certain elements of novelty;

- The implementation of a project is always associated with changes in some system and is its deliberate transfer from the existing to some desired state.

These signs, although they are being realized in the new conditions, are quite consistent with the traditional concept of design, namely: design is a set of works aimed at obtaining descriptions of a new or modernized technical object, sufficient to implement or manufacture the object in the given conditions. The target function of project management is the implementation of the project, which ensures the required quality of the final results of the project with the highest possible efficiency with restrictions on time, financial and material resources.

It is important to note that in general, project management is a strategic direction for the development of the state, which was approved by a government decree and serves as the basis for the implementation of priority programs. At the same time, the requirements for the participants in the project activity in terms of their qualifications in this area were approved. Thus, the formation of the competence of the project approach is an urgent task at all levels.:

- Education;

- Education at all levels (from elementary school to graduate school);

- Project management and implementation of the project approach in companies;

- Project management in government programs.

Currently, the competencies of the project approach are formed in the framework of solving all of the above problems. In particular, the composition of a single set of professional competencies of project management specialists has been clarified.

\subsection{Needs and opportunities in the formation of new competencies in the conditions of digitalization}

The project as a form of organization of activity provides for such a thing as teamwork. Therefore, project management requires not only the formation of competencies of managers, but also the creation of a workable project team. Each project participant solves the individual tasks that the project manager sets, but there are tasks that can be solved exclusively in a collective interaction. Even the elementary decomposition of a key project task is fully carried out in collective creativity. Formation of a project team is an important part of prelaunch preparation and an essential block of work during the project implementation period. Moreover, a shared leadership approach is being used when it is possible to perform different leadership functions by different team leaders, the most successful in this particular part of leadership. The concept of shared leadership [2] helps to 
maximally involve all project team members in the project activity, help them realize their potential, and strengthen the motivational effect of participating in the project work.

The formation of competencies of the project approach in educational programs has its own characteristics. In the traditional approach, the student receives an individual task for the projects and as a result of their implementation, a complete set of competencies is formed, since the task to be solved by each individual student requires the application of all the skills acquired during the training. However, at the same time, collective design skills necessary in future work are not formed enough.

In addition to the relevance of the formation of project competencies as part of team work, the task of informatization of education and the use of information and communication technologies in the educational and upbringing process come to the fore. The following terms are used: a single information and educational environment (EIOS), a single information and educational space, electronic educational environment. With all the variety of terms, it should be noted that EIOS is an automated system (AS), i.e. organizational and technical system that provides solutions based on the automation of information processes in various fields of activity (management, design, manufacturing, etc.) or their combinations. ASs implement information technology in the form of a specific sequence of information-related functions, tasks or procedures performed in automated (interactive) or automatic modes. The development of a new information environment is key in the development of new competencies, namely, preparation for work in digitalization.

Recently, new information technologies have appeared to support team project work. Owing to their novelty, the experience of applying in team design training is not great. In this article, we consider the informational support of the project approach, which is implemented in the most modern software products. As a project, we take the urgent task of group control of heterogeneous robots, which is distinguished by a hierarchical structure. Such a task is especially interesting for its duality, i.e. subject of research (group management) corresponds to the information technology of group design.

\section{General approaches to the task of group control of robots}

Now, many articles are devoted to the formulation and implementation of the tasks of group control of robots. Among them should be highlighted set of problems.

\subsection{Generalized functional schemes of group control strategy in multi-agent robotic systems [5]}




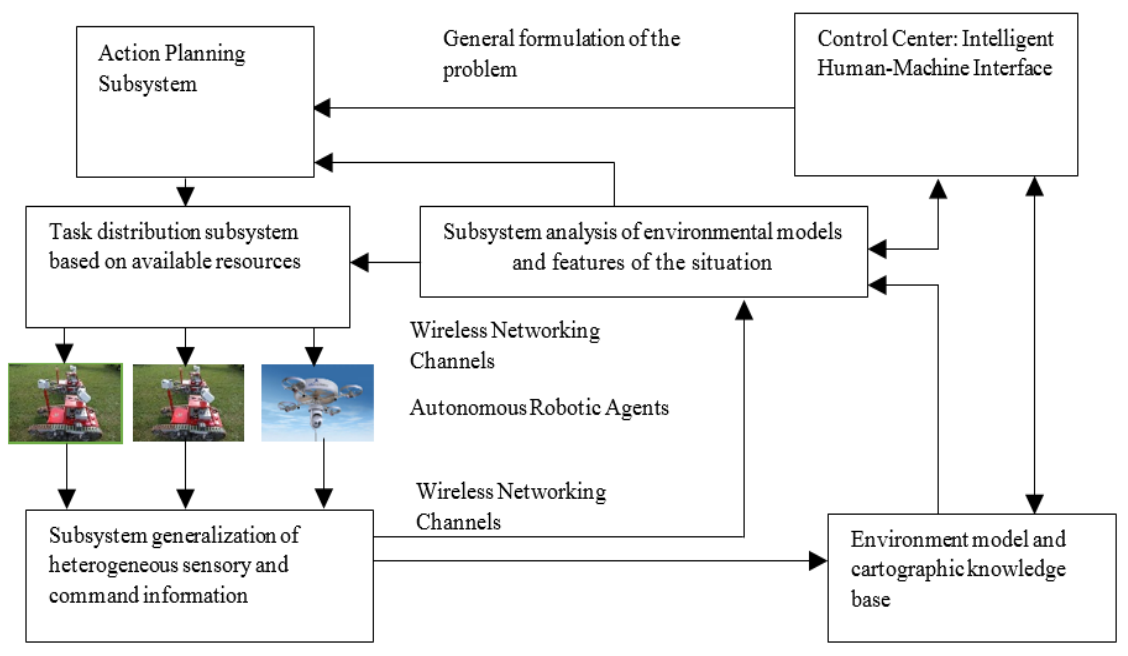

Fig. 1. Generalized functional structure of multi-agent robotic system [5].

\subsection{Development of algorithms}

As follows from the analysis of the functional model, the following algorithms are needed [4-18]:

\section{The main algorithms}

- Models and algorithms for action planning in multi-agent robotic systems. Most often, planning is the joint formation of trajectories of robot tasks that are fulfilled, which is implemented using multi-agent algorithms based on the potential method, for example, an algorithm for uniform distribution of robots in the work area and an algorithm for moving robots to target points in an environment with obstacles. To form trajectories, it is necessary to regularly determine the coordinates of robots in the workspace, which requires the construction of a combined navigation system.

- Methods and algorithms for the distribution of tasks in multi-agent robotic systems. Decomposition of global tasks solved by MRTS into simpler tasks and their distribution in the team leads, for example, to determining the coordinates of the target point for each robot.

- Methods and algorithms for planning optimal paths for robots from a group.

- Methods and algorithms for the synthesis of robot control systems from the group.

\section{Accessory algorithms}

- Compilation of heterogeneous sensory and command information

- Building a model of the environment

- Analysis of the model of the environment and environment

At the same time, various methods and algorithms for processing information are used. Information from the databases on the cartographic and meteorological conditions, including forecasting and others.

\section{Subsystem models}

- mobile robots;

- UAV type aircraft;

- copters. 


\section{The relationship of the features of the ongoing project of group control of robots and the in-depth formation of competencies in the training of specialists in robotics and mechatronics}

The concept of group design involves the fulfillment of one of the main requirements - the formation of mandatory in accordance with the standard of preparation, in this case - the educational institution's own approved educational standard of environmental management systems of BMSTU in the direction of master's training 04.15.06 "Mechatronics and Robotics" competencies for each of the project participants. Specific technical tasks within the framework of the group management project under consideration allow achieving this goal.

Since group control of heterogeneous robots is based on the management of many autonomous robots of various designs and functionality, the variety of designs makes it possible to expand the range of tasks performed by a group of robots. Also, the difference in the functionality of group members contributes to a more effective solution to the common problem, dividing it into sub-tasks that individual robots from the group can more successfully.

The quadcopter will analyze the terrain from the air. and perform the area monitoring functions in the group management project. In this case, the optimization problem was chosen as the central task [19]. Skills acquired in the design process cover a wide range of problems, such as optimizing the flight path, choosing the optimal altitude, optimizing energy consumption, choosing the optimal number of take-off and landing seats, as well as optimizing the frequency of image capture. This allows us to consolidate the theoretical knowledge of such disciplines as modern methods of control theory, optimal control theory, optimization methods and their application in the design of control systems for robotics and mechatronics objects, computer-aided design of information systems and technologies in mechatronics and robotics, methods, algorithms and hardware and software autonomous motion control of robotic systems and mechatronic systems.

For the second quadrocopter, the central problem was the task of ensuring movement along the chosen trajectory under the action of disturbing factors such as failure of the sensors responsible for collecting flight data, time of day, weather conditions.

The skills of the analysis of possible contingencies, along with the general design tasks, make the project not real-time, but real, which is the second most important condition for the formation of competencies. In this case, the mutual enrichment of skills and the intensification of the active development of the required professional competencies occur. Moreover, the development of the most important competence is achieved, namely, the ability to act in non-standard situations, be responsible for decisions made, use in practice acquired skills in organizing research and design work carried out by small groups of performers. This is the third major achievement that is achieved in the implementation of a group project.

Ground robots are wheeled and tracked vehicles that can directly control the terrain hidden for viewing from a quadrocopter using laser and television equipment. Since the project is real, it is necessary to solve the problem of moving around terrain with a difficult terrain and difficult terrain. The robot will be selected automatically, depending on the proximity of the location to the point, as well as the quality of the terrain of the investigated area. The caterpillar platform, in comparison with the wheeled, has increased cross-country ability, ease of control and the presence of a simpler chassis. Orientation to the practical use of a mobile robot involves the determination of not only profile, but also support patency, for which it is necessary to take into account the properties of soil diversity. 
A separate practical task is the energy supply of all robots in the group, and here it is desirable to use new approaches. So, to optimize the charging process of the quadrocopter, a mobile charging platform based on inductive charging can be implemented.

Another urgent problem for the project under consideration is the use of man in the system control loop [19-21]. For example, based on data from a quadrocopter and other robots, a human operator who monitors the work of the group has the opportunity to indicate a specific research point on a map of the area. The designed group management system refers to systems with a shared autonomy shared autonomy system, which are designed to bridge the gap between fully autonomous and fully human-controlled systems. Within the framework of the general task, a class of systems is distinguished that differ by switching control between a human operator and an autonomous controller to jointly achieve a specific control goal. A compromise is required between two possibly competing goals: achieving optimal performance to meet the limitations of temporal logic and minimizing human effort. In order to achieve the Pareto optimal solution, it is necessary to develop an algorithm that switches control between the operator and the stand-alone controller.

The most important difference of the project under consideration is that undergraduates master not only teamwork, but also gain valuable skills of mutual responsibility and their interaction as participants in the design process. The same interdependence should be mirrored in the developed robotic devices.

To solve the tasks, new software is actively used, for example, the formation of control logic (StateFlow) for solving extensive problems within the framework of the general task of group management. The concept of deep learning is used [22]. WEB-technologies are applied [23]. There is also a need for a comparative analysis of the capabilities of existing programs in creating new software. The principle of synthesis of individual design methods is used [24].

The completion of the practical part is the design of existing samples, writing a general test procedure and testing.

So, the group management project will help to form a deeper level of competencies:

- consolidation of theoretical material in the direction of training in the form of a knowledge system;

- coverage of the almost complete volume of development of the modern field of robotics;

- implementation of real design, involving the creation of objects with a software and hardware interface, including guaranteeing the necessary information interaction vertically and horizontally;

- transition to a new level of mastery of competencies, taking into account the real provision of the interconnected work of all systems and the combination in practice of a hierarchical block approach with new ideas for parallel design;

- formation of mutual responsibility and interaction of participants in the design process in a team.

\section{Formation of new representations of functional models}

Description of the composition of functional modules for direct modeling of development and operation processes requires more specificity. The following table 1 shows the results obtained by the author of the preparation for the project description, suitable for use in new information environments for project development. Full and abbreviated names are given - module names are highlighted (green), type - equipment (blue) and type — algorithm (orange). 
Table 1. Extended description of the group control project with entered type designations (model, algorithm), inputs, outputs of submodels.

\begin{tabular}{|c|c|c|}
\hline Submodel & Name / OutPut & Input \\
\hline $\begin{array}{c}\text { Control center: } \\
\text { Intelligent human-machine interface }\end{array}$ & ImmI & MainServer \\
\hline $\begin{array}{l}\text { Operational description and correction of } \\
\text { the General application problem }\end{array}$ & Global_Task & \\
\hline $\begin{array}{l}\text { Specification of operating environment } \\
\text { subject to limitations }\end{array}$ & Environment & Model_Real_Inveronment \\
\hline $\begin{array}{l}\text { Displays telemetry and sensor data about } \\
\text { the operation of individual agents }\end{array}$ & TSdata_agent & Info_Current_Inveronment \\
\hline $\begin{array}{l}\text { Displays telemetry and sensor data about } \\
\text { the interaction of individual agents }\end{array}$ & TSdata_invagent & Info_Current_Inveronment \\
\hline Action planning subsystem & SS_Plan & AlgoritnPlan \\
\hline Action planning & Plan & Global_Task \\
\hline The generation of jobs & Task & Info_Current_Inveronment \\
\hline $\begin{array}{l}\text { The current distribution of tasks between } \\
\text { the performers }\end{array}$ & SS_RaspTask_agent & AlgoritmRaspTask \\
\hline $\begin{array}{l}\text { The current distribution of tasks between } \\
\text { the performers }\end{array}$ & RaspTask_agent & $\begin{array}{l}\text { Plan } \\
\text { Task }\end{array}$ \\
\hline $\begin{array}{c}\text { Wireless communication channels to the } \\
\text { agents }\end{array}$ & SS_ConnectToAgent & ChannalLinkToAgent1...n \\
\hline Transfer of information to agents & LinkTask_ToAgent 1..n & RaspTask_agent $1 \ldots \mathrm{n}$ \\
\hline $\begin{array}{c}\text { Wireless communication channels from } \\
\text { agents }\end{array}$ & SS_ConnectFromAgent & ChannalLinkFromAgent $1 . . . n$ \\
\hline Transfer of information from agents & LinkTask_FromAgent & SensorAgent $1 \ldots \mathrm{n}$ \\
\hline Agent $1 \ldots n$ & Agent_1...n & Agent_1...n \\
\hline Agent $1-$ mobile robot or UAV & SensorAgent1 & LinkTask_ToAgent1 \\
\hline $\begin{array}{c}\cdots \\
\text { Agent } \mathrm{n} \\
\end{array}$ & SensorAgentn & LinkTask_ToAgentn \\
\hline $\begin{array}{c}\text { Subsystem of generalization of } \\
\text { heterogeneous sensor and command } \\
\text { information }\end{array}$ & SS_Info & AlgoritnInfo \\
\hline $\begin{array}{l}\text { Generalization of heterogeneous sensor } \\
\text { and command information }\end{array}$ & Analiz_Info & LinkTask_FromAgent \\
\hline Environment model building subsystem & SS_Model & AlgoritmModel \\
\hline Building a model of the environment & $\begin{array}{c}\text { Model_Real_Inveronme } \\
\text { nt }\end{array}$ & $\begin{array}{l}\text { Analiz_Info } \\
\text { ImmI }\end{array}$ \\
\hline $\begin{array}{c}\text { Subsystem analysis of the environment } \\
\text { model and environment }\end{array}$ & SS_Analis_Model & AlgoritmAnalizModel \\
\hline $\begin{array}{c}\text { Formation of information about the } \\
\text { current situation }\end{array}$ & $\begin{array}{c}\text { Info_Current_Inveronm } \\
\text { ent }\end{array}$ & $\begin{array}{c}\text { Analiz_Info; ImmI } \\
\text { Model_Real_Inveronment }\end{array}$ \\
\hline
\end{tabular}

For heterogeneous robots, the complexity of the hierarchy is characteristic, and the role of individual robots can change. Then the agent system in miniature can repeat the general system of Fig. 1, where part of the authority of the control center is transferred to one of the robots while maintaining the observation of the main control center. In this case, part of the subsystems is located on the control robot.

It also requires significantly greater specification of the functional models of individual intelligent robots. The author of this article significantly expanded the description of the 
structure, identified five main components: levels, algorithms, functions, equipment, signals, shown in Fig. 2

As a result of the analysis, the following areas of project development are formed:

- Development of a project hierarchy;

- Development of planning algorithms, decomposition, interaction;

- Data processing;

- Information transfer;

- Development of individual subsystems.

The types of components of the project are as follows:

- Functions

- Performers

- Equipment

- Algorithms

Obviously, functions and executors are inextricably linked, however, practical design is impossible without delegation of specific functions.

Putting mixed information into a single diagram in the form of a functional diagram requires close attention. Selecting layers is sometimes useful:

- Material objects

- Communications

- Algorithms

- Objectives

- External environment 


\begin{tabular}{|c|c|c|}
\hline Situation & $\begin{array}{l}\text { Object: Task } \\
\text { Specification }\end{array}$ & Map \\
\hline & $\downarrow$ & \\
\hline & $\begin{array}{c}\text { Strategic management } \\
\text { system level: } \\
\text { Sequence of actions } \\
\text { and decomposition: } \\
\text { Program, On-Board } \\
\text { Computer Intelligent } \\
\text { Control System }\end{array}$ & \\
\hline $\begin{array}{l}\text { Information and } \\
\text { measuring system }\end{array}$ & Target points $\{\mathrm{x}, \mathrm{y}, \mathrm{z}\}$ & Navigation system \\
\hline & $\downarrow$ & \\
\hline $\begin{array}{c}\text { Camcorders } \\
\text { Night-vision devices } \\
\text { Thermal Imagers } \\
\text { (Vision system) } \\
\text { Mono and stereo } \\
\text { vision }\end{array}$ & $\begin{array}{l}\text { Tactical level of the } \\
\text { control system: } \\
\text { movement in an } \\
\text { environment with } \\
\text { obstacles Program, } \\
\text { On-Board Computer } \\
\text { Intelligent Control } \\
\text { System }\end{array}$ & \\
\hline $\begin{array}{l}\text { Ultrasonic, Laser } \\
\text { Rangefinders } \\
\text { Robot obstacles }\end{array}$ & $\begin{array}{c}\text { Speeds and angular } \\
\text { position }\{\mathrm{V}, \varepsilon\}\end{array}$ & $\begin{array}{l}\text { Range finders } \\
\text { (lighthouses) }\end{array}$ \\
\hline $\begin{array}{c}\text { Local Area Map } \\
\text { (Program, On-Board } \\
\text { Computer) }\end{array}$ & 1 & $\begin{array}{l}\text { Recognition of the } \\
\text { reflective strip (Vision } \\
\text { system, Program, On- } \\
\text { Board Computer) }\end{array}$ \\
\hline $\begin{array}{l}\text { Road detector (Vision } \\
\text { system, Program, } \\
\text { On-Board Computer) }\end{array}$ & $\begin{array}{c}\text { Drive level control } \\
\text { system (control board) } \\
\text { Program, On-Board } \\
\text { Computer }\end{array}$ & $\begin{array}{c}\text { Radio navigation (GPS, } \\
\text { GLONASS, } \\
\text { pseudosatellites) }\end{array}$ \\
\hline $\begin{array}{l}\text { Inertial stabilizing } \\
\text { systems: Mechanical } \\
\text { gyroscopes, angular } \\
\text { velocity sensors, } \\
\text { Accelerometers, } \\
\text { Altitude sensors }\end{array}$ & $\begin{array}{l}\text { Control voltages }\{\mathrm{u}\} \\
\text { Amplifiers } \\
\text { Voltage on motor } \\
\text { windings }\end{array}$ & $\begin{array}{c}\text { Inertial navigation } \\
\text { systems. } \\
\text { Sensors inertial } \\
\text { navigation systems } \\
\text { Visual navigation }\end{array}$ \\
\hline & $\begin{array}{c}\text { Motor } \\
\text { Rotation of engine } \\
\text { shafts: speeds and } \\
\text { angles }\left\{q_{d}, q_{d}\right\} \\
\text { reduction gear }\end{array}$ & Feedback sensors \\
\hline Feedback sensors & $\begin{array}{c}\text { Robot: speeds and } \\
\text { angles }\{q, q\}, \\
\text { coordinates }\{x, y, z\}\end{array}$ & Wheel feedback sensors \\
\hline
\end{tabular}

Fig. 2. Advanced functional diagram of intelligent robot control system.

\section{Development of methods of application of modern information technologies for the formation of competencies in the field of group design}

It is proposed to consider the following areas for the development of new techniques in the field of application of new information technologies:

- Synthesis of various information technologies; 
- Application of a unified informational training and design environment.

\subsection{Application of CDP technology}

A parallel method - design is an approach to project activities in which all design disciplines and stakeholders are combined to create an integrated design in a joint mode of operation, providing good communication and information exchange between team members. The Concurrent Design Platform (CDP) consists in providing the environment and modeling capabilities necessary for the parallel development of all subsystems and their subsequent integration into a single system. CDP TM 4 is based on and conforms to the open design standard ECSS-E-TM-10-25 System Engineering - Engineering Design Model Data Exchange (CDF) [25]. CDP TM supports concurrent engineering and design processes (CD\&E), allowing multidisciplinary teams to work in accordance with the CD\&E methodology. It provides a collaborative work environment for collectivized groups through an intranet connection or geographically distributed groups through an Internet connection. CDP ${ }^{\mathrm{TM}}$ supports a clear separation of tasks and responsibilities according to the role assignment and advanced settings for determining access rights to the integrated design model in CDP TM.

To apply the parallel design method, the project must be complex and include a sufficiently differentiated interdisciplinary team. The analysis shows that the task of designing a group control of robots has all the necessary components for the successful implementation of parallel design (CD):

- Project activity - the project "group management of heterogeneous robots";

- A multidisciplinary group - for student projects there is a sufficient set of previously acquired knowledge and skills, including in the framework of inter-department interaction "

- Integrated design model - a set of functional models within the framework of a blockhierarchical approach;

- Software infrastructure (for example, CDP TM) - open source software products;

- Object (collocation) - a group of heterogeneous robots in specified operating conditions to achieve the goal.

The described technology allows you to identify several promising areas of the solution, evaluate the results of iterations. By comparing them, one can evaluate the improvements made by the team in reaching an adequate solution. Depending on the time, several of these iterations can be performed to create design alternatives, taking into account the various options. In CDP, users can be assigned to various roles that control what each specific user can do and see. The composition of the $\mathrm{CD}$ team for the task in question, taking into account the recommendations, includes the following roles:

- Project manager (in particular, the head of the master's program))

- System Assistant - given the novelty of the task, this is a system administrator

- Team leader (teacher directly supervising the work)

- Domain engineer (students in the group). For the problem under consideration, roles between engineers can be distributed as follows:

- Autonomous control system for a small UAV.

- Intelligent motion control system of the ground robot with adaptation to external conditions.

- Autonomous control system of a small-sized robot.

- Comparative analysis of active and passive vision systems for controlling the movement of a group of ground-based robots with recommendations.

- Promising vision systems and implementation for managing a group of robots in solving agricultural problems.

- Development of control algorithms for groups of heterogeneous robots. 
The advantages of this approach are its versatility and the ability to combine different information technologies. An alternative to the synthesis of such technologies is the use of a single informational training and design environment, which can be MATLAB [26].

\subsection{Application of System Composer in collective design}

The purpose of System Composer TM (the latest technology in 2019 at MATLAB ${ }^{\circledR}$ [26]) is the development and analysis of system and software architectures. It allows you to define, analyze and specify architectures and compositions for system design based on models and software design. System Composer distributes requirements while improving the architecture model, which you can then design and model in Simulink ${ }^{\circledR}$. System Composer allows you to create or import architecture models that describe the system in terms of components and interfaces. You can also populate an architecture model from the architectural elements of Simulink projects or $\mathrm{C} / \mathrm{C}++$ code. You can create custom realtime representations of a model to explore specific design or analysis tasks.

Fundamental to the developers of such a complex project as group control of robots, the property is the practical implementation of a block-hierarchical approach to design. The hierarchy model in architecture is built by decomposing components. Perhaps moving through the hierarchy. For the selected group management project, two hierarchy schemes were used, shown in Figs. 1, 2, and 3. The architecture model includes the top-level architecture that contains the system. This top-level architecture also allows you to define the interfaces of this system with other systems. For example, these are strategic, tactical, drive levels in the diagram of Fig. 3. A composition is a structured "parts list" - a hierarchy of components with their interfaces and connections. To develop the composition of the project in question, the information in Fig. 3 is used.

A component is a non-trivial, almost independent and replaceable part of a system that performs a clear function in the context of architecture. Such components are, for example, subsystems Fig. 1, 2 or elements of real equipment - engines, sensors, etc. fig. 3. A component element in System Composer can represent a component at any level in the hierarchy of the system, be it the main component of the system, which includes many subsystems,. for example, such as the Action Planning Subsystem, the Environment and Environment Model Analysis Subsystem of Fig. 2, the controller with its hardware and software, or a component at the lowest level of the hierarchy, for example, software - a messaging module. Each component in an architectural model can have its own design or even several alternative designs. These projects may be architectures modeled in System Composer ${ }^{\mathrm{TM}}$ or behaviors modeled in Simulink ${ }^{\circledR}$. For example, a block diagram for one agent may be typed in this package. Engineering systems often use the same component design in several places. As an example, these can be components of identical robots agents (Fig. 1). It is possible to reuse a component in System Composer both in the same model and in different architecture models. A detailed and debugged component can be recognized as a reference, for example, models of DC motors, accelerometers, gearboxes, etc. A component may have several design options. You can model options for any component in the same architectural model. You can define a combination of behaviors (defined in the Simulink model) and architectures (defined in the System Composer architecture model) as options. For example, a component may have two options, representing two alternative structural decompositions.

Designing a system and defining an architecture may include defining behavior for some components, such as the algorithm used for the data processing component. As such algorithms, Models and action planning algorithms in multi-agent robotic systems, etc. can be used. Components within System Composer ${ }^{\text {TM }}$ Architecture Models may have Simulink 
${ }^{\circledR}$ Behavioral Models. To do this, the behavior of the components is connected with Simulink models.

Spotlight tools are used to analyze complex projects. This is a simplified representation of the model, which captures the ascending and descending dependencies of a particular component of interest to developers. It is also important in order to form a complete set of competencies by students participating in the project with shared functions that can track the work of the designed system as a whole.

A system engineering solution includes a formal definition of interfaces between components. The connection simply shows that the two components have a connection output to input. Such relationships in the considered project use identifiers from Fig. 2. The interface defines the type, dimensions, units of measurement and data structure and is described using the interface editor.

The system requirements are implemented through the settings of the profile fields in which both a general criterion (at the top level of the hierarchy) and particular quality criteria are shown, for example:

- Cost of equipment

- Equipment weight communication line length

- Number of man-hours of development

- Failure time

- Reliability of nodes, etc.

By creating relationships between the component and the corresponding requirement, you can track whether all requirements are represented in the architecture. You can also synchronize requirements and design, for example, if the requirement changes or if the project requires a revision of the requirements. After the implementation of the project, an analysis is carried out for all fields presented in profiles.

\section{Results}

The result of constructing a model that implements the functional scheme of group management as a whole in accordance with Fig.1, Table 1, shown in Fig. 3. For a single agent in accordance with the scheme of Fig.2 the result is shown in Fig.4. Models of real equipment are included in the form of conventional Simulink units. 


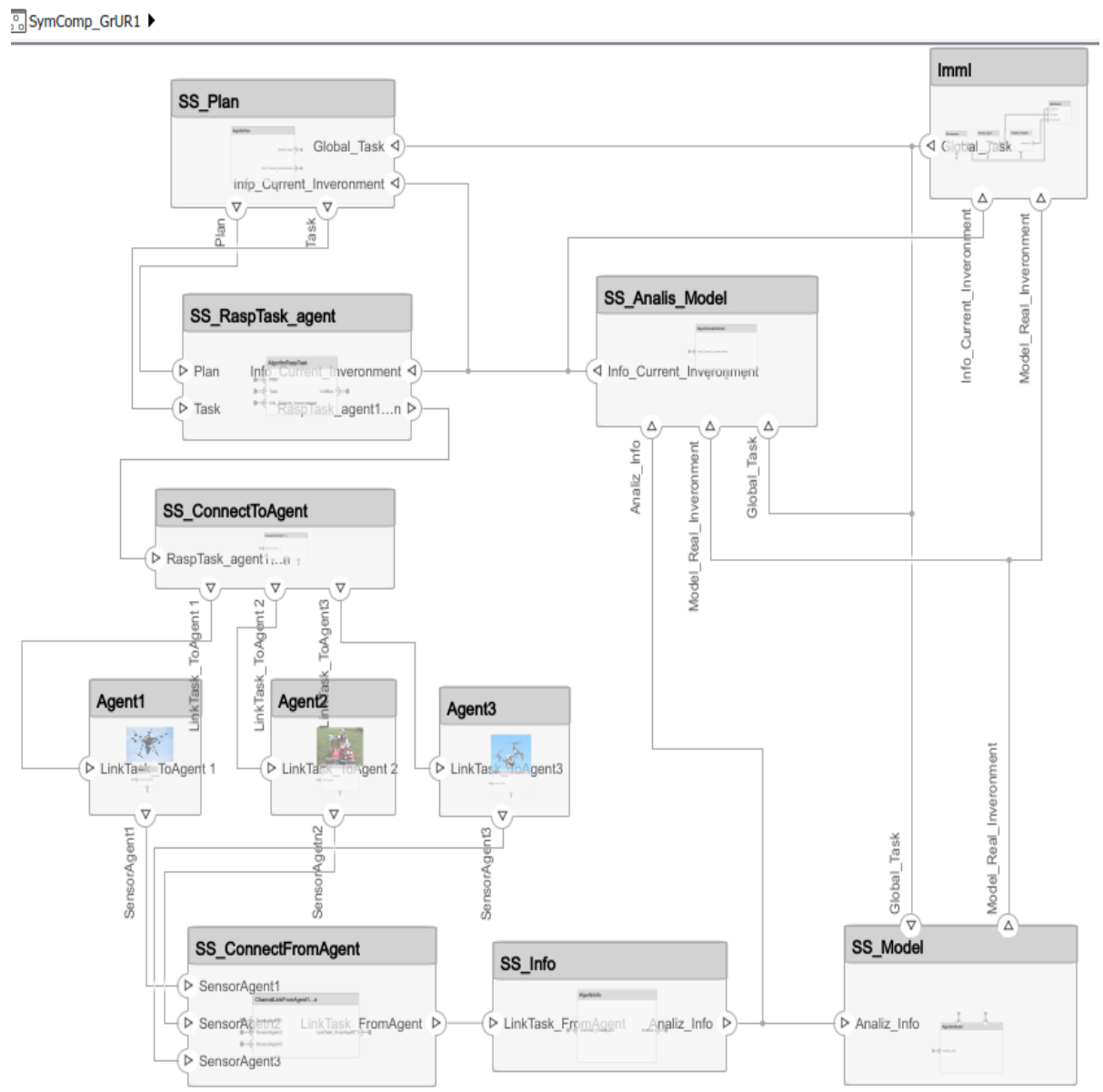

Fig. 3. Model Fig.1, Table. 1, assembled in System Composer. 


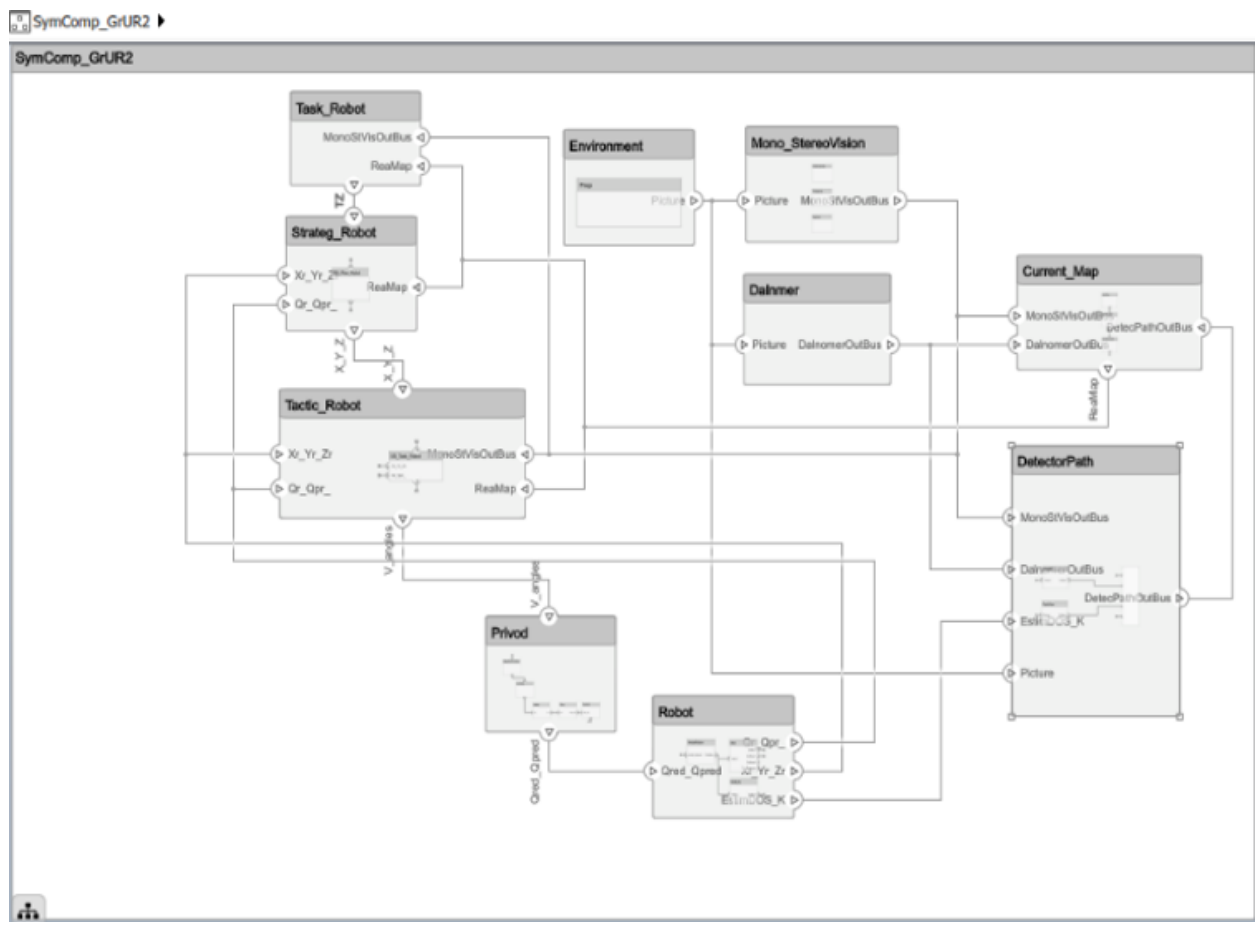

Fig.4. Model Fig.2, assembled in System Composer.

\section{Conclusion}

The relevance of the project approach in the areas of creating new facilities, education, training, public administration is shown. It is noted that competencies within the framework of the project approach can be successfully formed within the framework of new information technologies of parallel and compositional design. As an example of the applied design problem, the actual task of group control of heterogeneous robots is considered. The unique relationship of the object (group control) and the method of its research (group parallel design) is noted. A connection is established between the features of the ongoing project of group control of robots and the formation of in-depth competencies in the training of specialists in robotics and mechatronics. The applied problem is reformulated and adapted to implementation in accordance with the requirements of information technology CDP and System Composer. The models are obtained that implement the functional schemes of group management in two versions, suitable for use both for educational purposes of the formation of team project competencies and for implementation in real projects.

\section{References}

1. S.A. Borisov, A.F. Plekhanova, Sravnitel'nyy analiz proyektnogo i protsessornogo podkhodov v upravlenii, Rossiyskoye predprinimatel'stvo, № 13, p. 235 (2013)

2. S.N. Apen'ko, Povedencheskiye kompetentsii komandy proyekta v mezhdunarodnykh professional'nykh standartakh, Doklady 3-yey konferentsii «Molodezh' i upravleniye proyektami v Rossii: sovremennyye vyzovy i perspektivy, Vysshaya shkola ekonomiki (2013). www.pmcof.hse.ru 
3. V.M. Lokhin, S.V. Man'ko, M.P. Romanov, S.A-K. Diane, Perspektivy primeneniya, printsipy postroyeniya $i$ problemy razrabotki mul'tiagentnykh robototekhnicheskikh system, VESTNIK MGTU MIREA, № 3, Vol 1 (2015)

4. A. Kozov, The Stage Robot Simulator, Stage Manual. URL: http://rtv.github.io/Stage/ (7.06.2018).

5. X. Zhu, M. Gao, S. Li, A real-time Road Boundary Detection Algorithm Based on Driverless Cars, 4th National Conference on Electrical, Electronics and Computer Engineering, pp. 843-848 (2016)

6. N. Garnett, et al., Real-time category-based and general obstacle detection for autonomous driving, Proceedings of the IEEE Conference on Computer Vision and Pattern Recognition, pp. 198-205 (2017).

7. V.R. Guilherme, G.O. Manuel, R.R. Francisco, Robust Nonlinear Control for Path Tracking of a Quad-Rotor Helicopter, Vol. 17, I. 1, pp. 142-156 (2015)

8. T. Luukkonen, Modelling and control of quadcopter, pp.2-6 (2011)

9. L. Yang, J. Qi, D. Song, J. Han, Y. Xia, Survey of Robot 3D Path Planning Algorithms, Journal of Control Science and Engineering, p. 22 (2016). A. K. Jha, Intelligent Control and Path Planning of Multiple Mobile Robots Using Hybrid Ai Techniques, $\mathrm{PhD}$ thesis, p. 213 (2016)

10. O. Montiel, U. Orozco-Rosas, R. Sepúlveda, Path planning for mobile robots using Bacterial Potential Field for avoiding static and dynamic obstacles, Expert Systems with Applications, vol. 42(12), pp. 5177-5191 (2015)

11. Z. Liu, et al., Distributed sampled-data control of nonholonomic multi-robot systems with proximity networks, Automatica, vol. 77, pp. 170-179 (2017)

12. F. Bounini, D. Gingras, H. Pollart, D. Gruyer, Modified Artificial Potential Field Method for Online Path Planning Applications, IEEE Intelligent Vehicles Symposium (IV), pp. 1-7 (2017)

13. Anood Ibrahim1, Reba Rachel Alexander1, Mohammed Shahid Umar Sanghar1, Royson Donate Desouza2, Control Systems in Robotics, International Journal of Engineering Inventions e-ISSN: 2278-7461, p-ISSN: 2319-6491, Vol. 5, I. 5, pp. 29 38, May (2016)

14. Zool Hilmi Ismail and Nohaidda Sariff, A Survey and Analysis of Cooperative MultiAgent Robot Systems: Challenges and Directions, February 2nd 2018, Reviewed: June 6th 2018, Published: November 5th 2018. DOI: 10.5772/intechopen.79337.

15. S. G. Lee, Y. Diaz-Mercado, M. Egerstedt, MMultirobot control using time-varying density functions, IEEE Trans, Robot, 31(2), pp. 489-493 (2015). https://doi.org/10.1109/TRO.2015.2397771CrossRefGoogle Scholar.

16. A.Y. Fridman, SEMS-based control in locally organized hierarchical structures of robots collectives, A.E. Gorodetskiy, V.G. Kurbanov, (eds.), Smart Electromechanical Systems: The Central Nervous System, Studies in Systems, Decision and Control, Springer International Publishing, vol. 95, pp. 31-47, CrossRefGoogle Scholar, Switzerland (2017)

17. A.E. Gorodetskiy, I.L. Tarasova, Situational control a group of robots based on SEMS, A.E. Gorodetskiy, I.L. Tarasova (eds.), Smart Electromechanical Systems: Group Interaction. Studies in Systems, Decision and Control, vol. 174, p. 337, Springer, 03 November (2019). https://doi.org/10.1007/978-3-319-99759-9Google Scholar. 
18. Qiangqiang Zhao, Junkang Guo, Dewen Yu, A novel approach of input tolerance design for parallel mechanisms using the level set method, July 12 (2019). https://doi.org/10.1177/0954405419863228.

19. I.K. Romanova, Multi-objective optimization of dynamic systems and problem of the Pareto front control, AIP conference Proceedings, 2171, 110016 (2019). htpps://doi.org/10.1063/1.5133250.

20. S.G. Liu, Q. Jin, C. Liu, Analytical method for optimal component tolerances based on manufacturing cost and quality loss, Proc IMechE, Part B: J Engineering Manufacture 2013, No. 227, pp. 1484-1491 (2013)

21. N. Jawahar, R. Sivasankaran, M. Ramesh, Optimal Pareto front for manufacturing tolerance allocation model, Proc IMechE, Part B: J Engineering Manufacture 2017; No. 231, pp. 1190-1203 (2017)

22. Alexander Lavin, Pareto Front-Based Multiobjective Path Planning Algorithm, Cornell University, Computer Science > Robotics. https://arxiv.org/abs/1505.05947 22 May 2015eeding 2171.

23. Ya. LeCun, B. Yoshua, H. Geoffrey, Deep learning, Nature, vol. 521, pp. 436-444 (2015)

24. A.V. Barenji \& C. Değirmenci, Robot Control System based on Web Application and RFID Technology, MATEC Web of Conferences, Vol. 28, p. 04001, EDP Sciences. -9 (2015)

25. Jessica T. DeCuir-Gunby \& Paul A. Schutz, Mixed Methods Designs: Frameworks for Organizing Your Research Methods, Developing a Mixed Methods Proposal: A Practical Guide for Beginning Researchers (2017). DOI: https://dx.doi.org/10.4135/9781483399980.n10

26. ECSS-E-TM-10-25 System Engineering - Engineering Design Model Data Exchange (CDF).

27. System Composer $\mathrm{TM} /$ www.mathworks.com. 